Available online at http://jurnal.goretanpena.com/index.php/JSSR

\title{
PREDIKSI PEMINATAN PROGRAM STUDI PADA PENERIMAAN MAHASISWA STMIK ROYAL MENGGUNAKAN NAÏVE BAYES
}

\author{
Wiwin Handoko ${ }^{1}$, Muhammad Iqbal ${ }^{2}$ \\ ${ }^{1,2}$ Sistem Informasi, Sekolah Tinggi Manajemen Informatika dan Komputer Royal \\ Email: ${ }^{1}$ win.van.handoko@gmail.com, ${ }^{2}$ codeegoc@ gmail.com
}

\begin{abstract}
STMIK Royal has 2 majors, namely Information Systems and Computer Systems. Almost every year at the time of admission of new students, there is a decrease in the interest of prospective students who choose the Computer Systems major, while the Information Systems major shows an increasing trend. Especially for the Computer Systems department, this decline will certainly have an impact on the development and quality of the department in the future. To overcome this, it is possible to predict the specialization of majors in new student admissions. If the prediction that appears is the Computer Systems major, the prospective student will be given a special reward so that it is hoped that interest for other prospective students will increase. Naïve Bayes is one of the classification algorithms in data mining that can be used to predict this. Based on the tests that have been carried out, the system can provide predictions with an accuracy rate of $65 \%$.
\end{abstract}

Keywords: Prediction, Majors, Naïve Bayes, Accuracy

\begin{abstract}
Abstrak: STMIK Royal memiliki 2 Program Studi yaitu Sistem Informasi dan Sistem Komputer. Hampir tiap tahun pada saat penerimaan mahasiswa baru, terjadi penurunan minat calon mahasiswa yang memilih Program Studi Sistem Komputer sedangkan untuk Program Studi Sistem Informasi menunjukkan tren yang terus meningkat. Khusus untuk Program Studi Sistem Komputer, penurunan ini tentunya akan berdampak bagi perkembangan dan kualitas Program Studi tersebut kedepannya. Untuk mengatasi hal tersebut dapat dilakukan prediksi peminatan Program Studi pada penerimaan mahasiswa baru. Apabila prediksi yang muncul adalah Program Studi Sistem Komputer, maka calon mahasiswa tersebut akan diberikan reward khusus sehingga diharapkan minat untuk calon mahasiswa yang lain akan semakin meningkat. Naïve Bayes merupakan salah satu Algoritma klasifikasi dalam data mining yang dapat digunakan untuk memprediksi hal tersebut. Berdasarkan pengujian yang telah dilakukan, sistem dapat memberikan prediksi dengan tingkat akurasi $65 \%$.

Kata kunci: Prediksi, Program Studi, Naïve Bayes, akurasi
\end{abstract}

\section{PENDAHULUAN}

Setiap Perguruan Tinggi terutama kampus swasta tentunya berharap dapat menghasilkan lulusan yang berkualitas dan berdaya saing. Namun dalam menghasilkan lulusan yang berkualitas tentunya tidak terlepas dari input calon mahasiswa dalam proses penerimaan mahasiswa baru (Suryadi \& Harahap, 2018). STMIK Royal merupakan salah satu kampus swasta yang berada di Kota
Kisaran Kabupaten Asahan Provinsi Sumatera Utara. Saat ini STMIK Royal memiliki 2 Prodi yaitu Sistem Informasi dan Sistem Komputer. Hampir tiap tahun pada saat penerimaan mahasiswa baru, terjadi penurunan minat calon mahasiswa yang memilih Prodi Sistem Komputer sedangkan untuk Prodi Sistem Informasi menunjukkan tren yang terus meningkat. Khusus untuk Prodi Sistem Komputer, penurunan ini tentunya akan berdampak bagi perkembangan dan kualitas prodi 
Available online at http://jurnal.goretanpena.com/index.php/JSSR

tersebut kedepannya. Tidak adanya mahasiswa, bahkan penutupan prodi bisa saja terjadi. Permasalahan ini harus segera ditangani oleh pimpinan akademik maupun yayasan dalam rangka meningkatkan kembali minat dan jumlah mahasiswa prodi Sistem Komputer. datadata yang terkait harus segera dikumpulkan dan dianalisa untuk mendapatkan alternatif solusi yang baik. Salah satu alternatif solusi yang dapat dilakukan adalah pencarian insight pada dataset penerimaan mahasiswa baru gelombang pertama Tahun Akademik 2021/2022. Dari insight tersebut diharapkan dapat memberikan gambaran distribusi sebaran asal daerah mahasiswa yang memilih Program Studi Sistem Informasi dan Sistem Komputer. selanjutnya dari data sebaran tersebut akan dibuatkan sebuah model yang akan dapat memprediksi peminatan program studi pada penerimaan mahasiswa baru pada gelombang yang berikutnya. Model yang digunakan pada penelitian ini adalah Naïve Bayes. Apabila prediksi yang muncul adalah Prodi Sistem Komputer, maka calon mahasiswa tersebut akan diberikan reward khusus sehingga diharapkan minat untuk calon mahasiswa akan semakin meningkat.

Data mining adalah proses ekstraksi untuk menemukan sebuah arti, pola dan kebiasaan baru dengan memilahmilah sebagian besar data yang disimpan dalam media penyimpanan dengan menggunakan pengenalan pola seperti teknik statistik dan matematika (Mafakhir \& Solichin, 2020). Data mining terbagi beberapa kelompok pembahasan salah salah satunya adalah klasifikasi (Classifier). Dalam klasifikasi terdapat sebuah metode yaitu Naïve Bayes. Algoritme Naïve Bayes merupakan suatu metode pengklasifikasian data dengan model statistik yang dikemukakan oleh ilmuan Inggris Thomas Bayes dan dapat digunakan untuk memprediksi probabilitas keanggotaan pada suatu kelas yaitu memprediksi peluang di masa depan berdasarkan pengalaman dimasa sebelumnya (Lianda \& Atmaja, 2021).
Berikut bentuk umum dari teorema Naïve Bayes:

$$
\begin{aligned}
& P(H \mid X) \\
& =\frac{\mathrm{P}(\mathrm{X} \mid \mathrm{H}) \mathrm{P}(\mathrm{H})}{\mathrm{P}(\mathrm{X})}
\end{aligned}
$$

Keterangan:

$\mathrm{X}=$ Data dengan class yang belum diketahui

$\mathrm{H}=$ Hipotesis data $\mathrm{X}$ merupakan suatu class spesifik

$\mathrm{P}(\mathrm{H} \mid \mathrm{X})=$ Probabilitas hipotesis $\mathrm{H}$ berdasarkan kondisi $\mathrm{x}$ (posteriori prob.)

$\mathrm{P}(\mathrm{H})=$ Probabilitas hipotesis $\mathrm{H}$ (prior prob.)

$\mathrm{P}(\mathrm{X} \mid \mathrm{H})=$ Probabilitas $\mathrm{X}$ berdasarkan kondisi tersebut

$\mathrm{P}(\mathrm{X})=$ Probabilitas dari $\mathrm{X}$

\section{METODE}

Metodologi Penelitian merupakan tahapan sistematis yang harus dilalui dalam penelitian untuk membantu penelitian menjadi terarah dengan baik (Ristianto \& Yoraeni, 2021). Pengolahan data pada penelitian ini menggunakan python. Berikut tahapan yang yang dilakukan untuk melakukan prediksi dengan menggunakan naïve bayes pada penelitian ini:

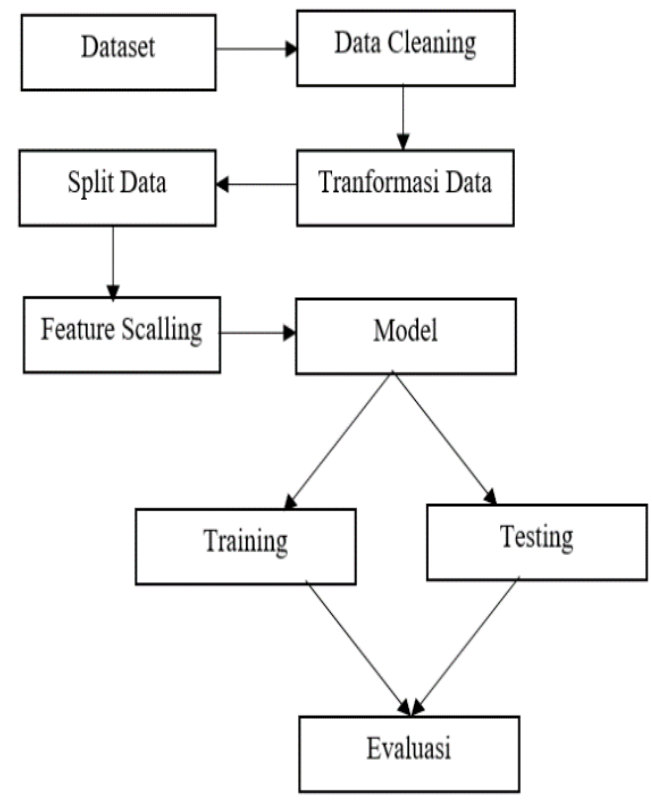

Gambar 1. Tahapan Pengolahan Data 
Available online at http://jurnal.goretanpena.com/index.php/JSSR

Dataset

Dataset yang digunakan pada penelitian ini adalah data penerimaan mahasiswa baru gelombang pertama Tahun Akademik 2021/2022 dalam bentuk file excel (.xlsx)

\section{Data Cleaning}

Data Cleaning merupakan tahapan yang dilakukan untuk menangani data apabila terjadi missing value, membuang kolom yang tidak terlalu digunakan maupun imbalance pada data.

Transformasi data

Tranformasi data merupakan tahapan preprocessing yang dilakukan untuk mengubah data agar dapat dibaca oleh mesin.

\section{Split Data}

Split data merupakan tahapan yang dilakukan untuk membagi dataset menjadi dua bagian yaitu data training dan data testing

Feature scalling

Feature scalling merupakan tahapan yang digunakan untuk melakukan normalisasi atau standarisasi nilai yang ada variabel fitur.

\section{Model}

Model merupakan tahapan yang digunakan untuk membuat sebuah model yang akan digunakan untuk mengolah data.

Evaluasi

Evaluasi merupakan tahapan yang digunakan untuk mengukur sejauh mana kualitas hasil dari model yang dipakai.

\section{HASIL DAN PEMBAHASAN}

Pada bagian ini, akan dijelaskan hasil penelitian yang sudah di uji coba dengan model prediksi sesuai dengan pembahasan yang ada di bab sebelumnya mulai dari import dataset sampai evaluasi dengan menggunakan python.

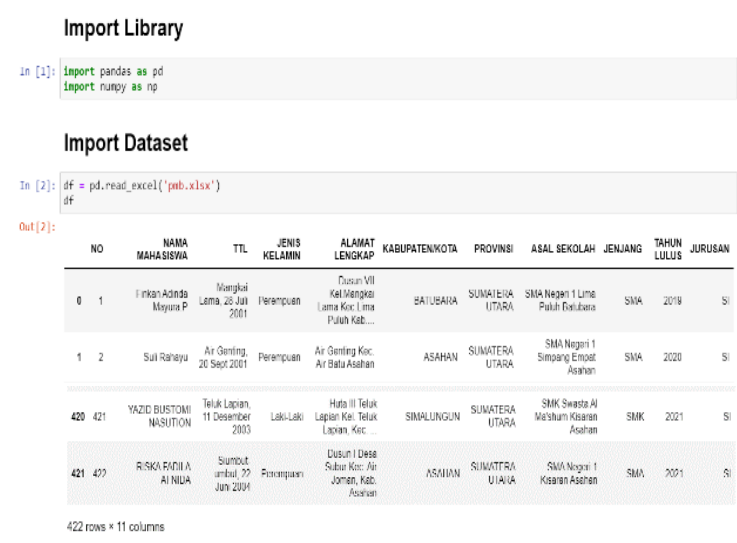

Gambar 2. Import Dataset

Pada gambar 2 dataset yang diimport kedalam jupyter notebook adalah data penerimaan mahasiswa baru gelombang pertama dimana terdapat 422 baris dan 11 kolom. Tahap selanjutnya adalah data cleaning

\section{Data Cleaning}

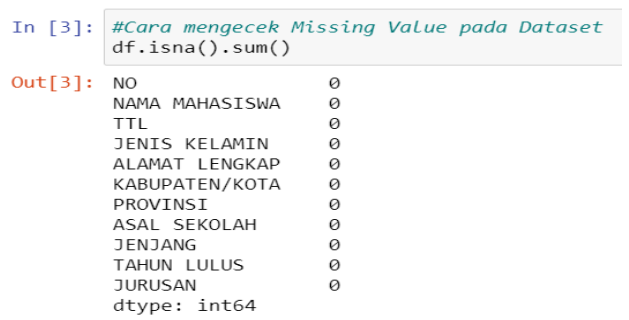

\section{Gambar 3. Mengecek Missing Value}

Pada gambar 3, setelah dilakukan data cleaning, missing value tidak ditemukan pada dataset. selanjutnya kita dapat melakukan Visualisasi untuk melihat insight pada dataset. Kolom Jurusan pada Dataset ini merupakan variabel target sedangkan kolom yang lainnya variabel fitur.

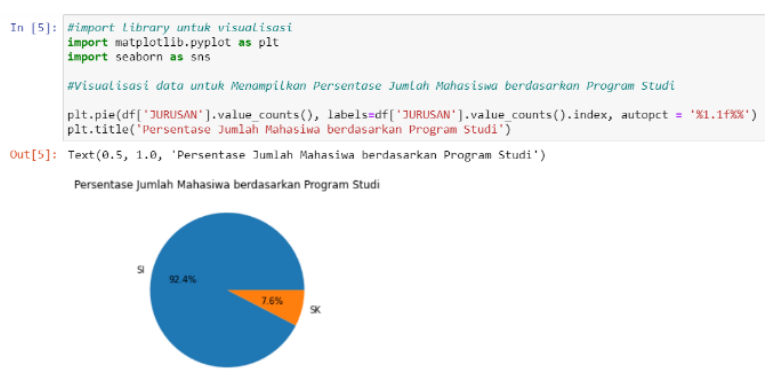

Gambar 4. Visualisasi Dataset 
Available online at http://jurnal.goretanpena.com/index.php/JSSR

berdasarkan hasil visualisasi diatas, kita dapat menemukan Imbalance data, dimana Jumlah mahasiswa untuk yang memilih Program Studi Sistem Informasi sebanyak 92\% (390 Orang) dan Sistem Komputer $7.6 \%$ (32 Orang). untuk mengatasi hal tersebut kita dapat menggunakan berbagai metode. pada kasus ini akan menggunakan metode Random Undersampling

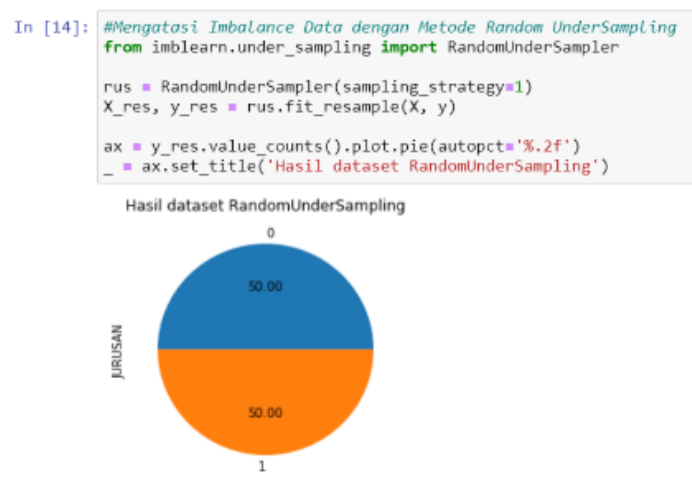

\section{Gambar 5. Visualisasi Setelah Resample}

Pada gambar 5, dataset sudah menjadi balance dengan komposisi 50 : 50 untuk masing-masing program studi (32 orang untuk Sistem Informasi dan 32 orang untuk Sistem Komputer). Tahap berikutnya adalah tranformasi data

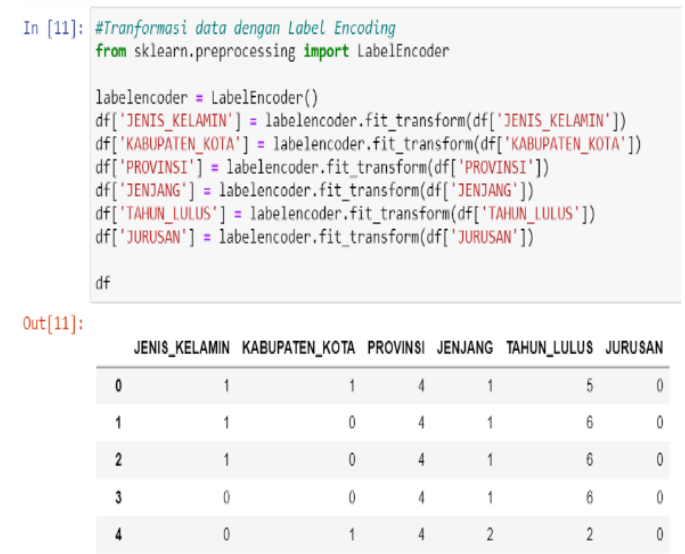

Pada gambar 6, dilakukan tranformasi data dengan menggunakan metode Label Encoding untuk kolom yang akan digunakan dalam pengolahan data.

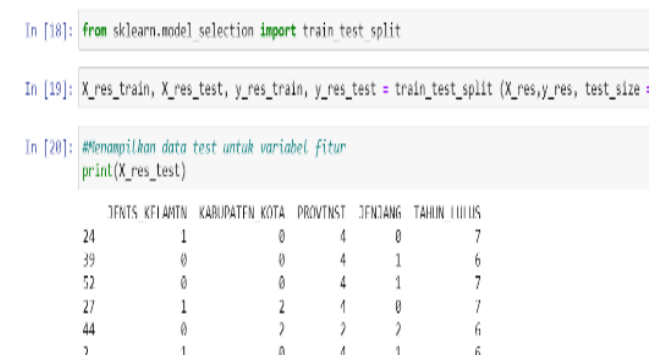

\section{Gambar 7. Split Data}

Pada gambar 7, Selanjutnya kita melakukan split data untuk membagi dataset menjadi dua bagian yaitu data training dan data test. pada kasus ini dataset dibagi $70 \%$ untuk data training dan $30 \%$ untuk data test.

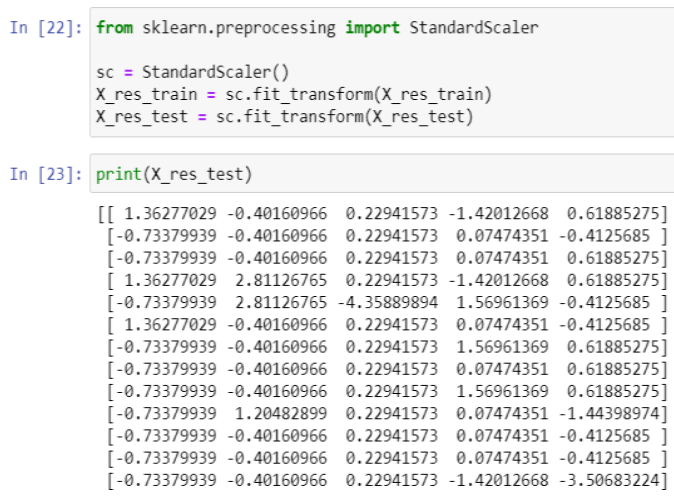

Gambar 8. Feature Scalling

Pada gambar 8 dilakukan feature scalling. Feature Scalling yang digunakan pada kasus ini adalah Standarization.

\section{Training}

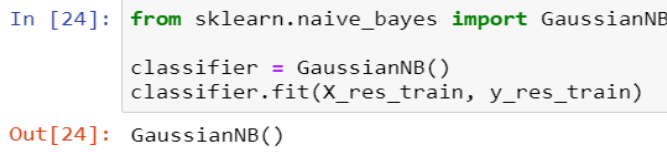

Gambar 9. Pembuatan Model 
Available online at http://jurnal.goretanpena.com/index.php/JSSR

Pada gambar 9, dibuat sebuah model naïve bayes untuk melakukan training dan testing pada dataset.

\section{Evaluasi}

In [26]: from sklearn,metrics import confusion_matrix,accuracy_score

$$
a c=\text { accuracy_score(y_res_test, y_pred) }
$$

In [27]: print("Tingkat Akurasi dengan menggunakan Naive Bayes sebesar ", ac)

Tingkat Akurasi dengan menggunakan Naive Bayes sebesar 0.65

\section{Gambar 10. Evaluasi}

Pada gambar 10, dilakukan evaluasi untuk mengukur kualitas dari hasil model yang telah dibuat. Berdasarkan pengujian untuk kasus ini, tingkat akurasi dengan menggunakan naïve bayes adalah $65 \%$

\section{SIMPULAN}

Berdasarkan penelitian dan pengujian yang telah dilakukan dapat disimpulkan bahwa algoritma naïve bayes dapat melakukan prediksi terhadap peminatan program studi pada penerimaan mahasiswa baru STMIK Royal dengan tingkat akurasi $65 \%$.

\section{DAFTAR PUSTAKA}

Lianda, D., \& Atmaja, N. S. (2021). Prediksi Data Buku Favorit Menggunakan Metode Naïve Bayes (Studi Kasus: Universitas Dehasen Bengkulu). Pseudocode, 8(1), 2737.

https://doi.org/10.33369/pseudocode .8.1.27-37

Mafakhir, A. Z., \& Solichin, A. (2020). Penerapan Metode Naïve Bayes Classifier Untuk Penjurusan Siswa Pada Madrasah Aliyah Al-Falah Jakarta. Fountain of Informatics Journal, $\quad 5(1), \quad 21$. https://doi.org/10.21111/fij.v5i1.400 7

Ristianto, F., \& Yoraeni, A. (2021). Impementasi Metode Naive Bayes Untuk Prediksi Harga Emas. Jurnal CO-SCIENCE (Computer Science), I(1), 62-71. http://jurnal.bsi.ac.id/index.php/coscience/article/view/201

Suryadi, A., \& Harahap, E. (2018). Sistem Rekomendasi Penerimaan Mahasiswa Baru Menggunakan Naive Bayes Classifier Di Institut Pendidikan Indonesia. Joutica, 3(2), 171.

https://doi.org/10.30736/jti.v3i2.231 